\title{
Pengaruh Jarak Tanam dan Jenis Stek Terhadap Kecepatan Penutupan Arachis pintoi Krap. \& Greg. Sebagai Biomulsa Pada Pertanaman Tomat (Licopersicon esculentum M.)
}

\section{Effect of Density and Type of Cutting on The Coverage of Arachis pintoi as Biomulch on Tomatoes Cultivation}

\author{
Yudi Febrianto, M.A. Chozin* \\ Departemen Agronomi dan Hortikultura, Fakultas Pertanian, Institut Pertanian Bogor \\ (Bogor Agricultural University), Jl. Meranti, Kampus IPB Dramaga, Bogor 16680, Indonesia \\ Telp \& Faks. 62-251-8629353 e-mail agronipb@indo.net.id \\ *)Penulis untuk korespondensi : ma chozin@yahoo.com
}

Disetujui 24 Desember 2013/ Published online 13 Februari 2014

\begin{abstract}
This research was conducted in Cikabayan Experimental Field, Bogor from December 2011 to May 2012. The objective of this research was to study the effect of different types of cuttings and planting density of A. pintoi speed coverage and to find out the effect of Arachis pintoi as biomulch on the growth and the yield of tomato. The factorial experiment was arrangement in Randomized Completely Block Design with three replication. First factor was the types of cutting (bottom, middle, top) and the second factor was the density of planting (K1: $20 \mathrm{~cm} \times 20 \mathrm{~cm} ; K 2: 20 \mathrm{~cm} \times 15 \mathrm{~cm} ; K 3: 20 \mathrm{~cm} \times 10 \mathrm{~cm} ; K 4: 20 \mathrm{~cm} \times 5 \mathrm{~cm}$ ). The result of this research is that the density of planting and the cuttings factors were significant effect on increasing the coverage, but the interaction was not significant. K4 and K3 treatment are faster than K2 and $K 1$ treatment on coverage speed. The treatments were not significant effect on the growth and the yield of tomato. The coverage of $A$. pintoi can reduce the dry weight of weeds and able to increase the weight of tomato per plant.
\end{abstract}

Keywords :Biomulch, A. pintoi, land coverage, tomato, weed

\begin{abstract}
ABSTRAK
Penelitian dilakukan di Kebun Percobaan Cikabayan Darmaga Bogor dari bulan Desember 2011 Mei 2012. Tujuan penelitian untuk mempelajari pengaruh jenis stek dan jarak tanam tanam terhadap kecepatan penutupan A. pintoi dan pengaruhnya terhadap pertumbuhan serta hasil tanaman tomat. Rancangan yang digunakan adalah Rancangan Kelompok Lengkap Teracak (RKLT) dengan 3 ulangan. Perlakuan terdiri dari 2 faktor yaitu jenis stek ( pangkal, tengah, pucuk) dan jarak tanam tanam (K1: $20 \mathrm{~cm}$ $x 20 \mathrm{~cm} ; K 2: 20 \mathrm{~cm} \times 15 \mathrm{~cm} ; \mathrm{K} 3: 20 \mathrm{~cm} \times 10 \mathrm{~cm} ; \mathrm{K} 4: 20 \mathrm{~cm} \times 5 \mathrm{~cm})$. Hasil penelitian menunjukkan perlakuan jarak tanam dan jenis stek nyata dapat meningkatkan persen penutupan tanah, sedangkan interaksinya tidak berpengaruh nyata. Perlakuan K4 dan K3 lebih cepat penutupanya disbanding K2 dan K1. Perlakuan tidak berpengaruh nyata terhadap pertumbuhan dan komponen hasil tanaman tomat. Penutupan dapat mengurangi berat kering gulma dan mampu meningkatkan bobot buah tomat per tanaman.
\end{abstract}

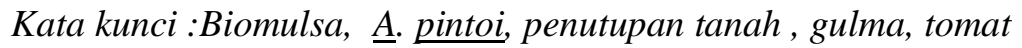

\section{PENDAHULUAN}

Buah tomat saat ini merupakan salah satu komoditas hortikultura yang bernilai ekonomi tinggi dan masih memerlukan perhatian, terutama dalam hal peningkatan hasil dan kualitas buahnya. Buah tomat merupakan sumber vitamin A dan C yang sangat baik. Kandungan lycopen pada tomat sangat berguna untuk kesehatan sebagai antioksidan yang dapat mencegah perkembangan penyakit kanker.

Upaya peningkatan produksi terus dilakukan untuk mendapatkan hasil yang optimal. Permasalahan gulma sering menjadi penyebab penurunan produksi karena terjadinya kompetisi air, hara, dan cahaya. Salah satu alternatif teknik 
budidaya yang dilakukan untuk mengurangi atau menghambat tumbuhnya gulma adalah pemanfaatan mulsa. Menurut Sumarni (2009) mulsa dapat berbentuk mulsa anorganik mupun mulsa organik. Penggunaan mulsa organik dapat memberikan manfaat bagi kelestarian lingkungan. Penggunaan mulsa organik diantaranya tanaman penutup tanah jenis kacang-kacangan atau legum.

Penutupan permukaan tanah dengan sisasisa tanaman atau tanaman penutup tanah (biomulsa) merupakan teknik konservasi secara vegetatif atau kultur teknis yang mudah dilaksanakan. Adanya tanaman penutup tanah dan mulsa organik dapat menahan percikan air hujan dan aliran air di permukaan tanah sehingga pengikisan lapisan atas tanah dapat ditekan. Tanaman kacang tanah merupakan tanaman penutup tanah paling baik untuk penanaman cabai karena memberikan peningkatan hasil cabai paling tinggi yaitusebesar $33,91 \%$ dengan penurunan tingkat erosi tanah sebesar $39,65 \%$ (Sumarni et al 2006).

Kendala pada penggunaan biomulsa adalah kompetisi hara antara tanaman pokok dengan penutup tanah. Menurut Baharuddin (2010) produksi tomat pada perlakuan biomulsa A. pintoi hasilnya masih lebih rendah dibandingkan dengan penggunaan mulsa plastik hitam perak. Rendahnya jumlah buah tomat pada lahan dengan biomulsa $A$. pintoi diduga disebabkan oleh kompetisi hara antara tanaman tomat dengan gulma maupun A. pintoi. Penutupan A. pintoi yang lambat dan belum optimal menjadi penyebab tumbuhnya gulma yang dapat menggangu tanaman, sehingga diperlukan suatu usaha untuk memaksimalkan penutupan $A$. pintoi pada lahan.

Faktor yang berpengaruh terhadap kecepatan penutupan A. pintoi diantaranya adalah jarak tanam atau jarak tanam. Jarak tanam yang sesuai diharapkan dapat memberikan penutupan yang optimal sehingga berdampak positif terhadap produksi tanaman tomat. Faktor lain yang perlu diketahui pengaruhnya terhadap kecepatan penutupan adalah jenis asal bahan stek yang digunakan. Stek yang berasal dari pangkal batang, batang tengah dan bagian pucuk memiliki potensi pertumbuhan tunas dan akar berbeda. Menurut Hartman (1997) zat yang paling berpengaruh pada pengakaran stek adalah auksin. Auksin ini banyak terdapat pada bagian sekitar pucuk tanaman. Meskipun demikian, pengunaan stek bagian pucuk memiliki kelemahan respirasinya cepat sehingga mudah layu sebelum tumbuh akar atau tunas.

Tujuan dari penelitian ini adalah
1. Mempelajari pengaruh jenis stek dan jarak tanam tanam terhadap kecepatan penutupan $A$. pintoi.

2. Mengetahui interaksi antara jenis stek dan jarak tanam tanam terhadap kecepatan penutupan $A$. pintoi.

3. Mengetahui pengaruh penanaman A. pintoi terhadap pertumbuhan gulma.

4. Mengetahui pengaruh penanaman A. pintoi terhadap hasil produksi tanaman tomat.

\section{BAHAN DAN METODE}

Penelitian ini dilaksanakan di Kebun Percobaan Cikabayan, Darmaga dengan ketinggian $250 \mathrm{~m}$ dpl. Penelitian berlangsung dari bulan Desember 2011 sampai dengan Mei 2012. Bahan yang digunakan pada penelitian ini adalah benih tomat varietas Ratna, stek batang $A$. pintoi bagian pangkal, tengah, dan pucuk, bioaktif perangsang perakaran Rootone-F, pupuk kandang, urea, pupuk NPK. Alat yang digunakan dalam penelitian ini adalah peralatan budidaya tanam, alat ukur, timbangan, tray semai, oven.

Penelitian dilakukan menggunakan rancangan faktorial RKLT (Rancangan Kelompok Lengkap Teracak) dengan dua faktor yaitu faktor pertama jenis asal bahan stek $A$. pintoi terdiri dari stek batang pangkal (J1), stek batang tengah (J2), dan stek pucuk (J3). Faktor kedua yaitu jarak tanam penanaman $A$. pintoi terdiri dari jarak tanam $20 \mathrm{~cm}$ x $20 \mathrm{~cm}(\mathrm{~K} 1), 20 \mathrm{~cm} \times 15 \mathrm{~cm}(\mathrm{~K} 2)$, $20 \mathrm{~cm} \times 10 \mathrm{~cm}(\mathrm{~K} 3)$, dan $20 \mathrm{~cm} \times 5 \mathrm{~cm}$ (K4). Terdapat 12 kombinasi perlakuan pada setiap ulangan sehingga terdapat 36 satuan percobaan.

Pengolahan tanah pada bedengan berukuran $1,5 \mathrm{~m}$ x $5 \mathrm{~m}$. A pintoi yang akan ditanam berbentuk stek batang yang terdiri dari stek bagian pangkal, stek batang tengah, dan stek pucuk batang dengan masing-masing stek panjangnya empat ruas. Sebelum ditanam dilakukan perendaman dalam larutan bioaktif Rooton-F selama 12 jam dengan konsentrasi 400 $\mathrm{mg} / \mathrm{l}$. Penanaman dilakukan dengan membenamkan 2 ruas batang stek ke tanah. Pemupukan urea dengan dosis $100 \mathrm{~kg} \mathrm{~N} / \mathrm{ha}$ dilakukan pada saat penanaman $A$. pintoi dan umur 4 MST. Penyulaman dilakukan pada 1-3 MST. Pindah tanam tomat ke lapang dilakukan pada saat $A$. pintoi berumur 10 MST dan umur tomat 30 hari di persemaian. Jarak tanam yang digunakan $50 \mathrm{~cm} \times 60 \mathrm{~cm}$. Pemupukan tomat menggunakan pupuk NPK dengan konsentrasi 100 gram per 10 liter. Pemeliharaan meliputi 
penyulaman, penyiangan, pengendalian hama dan penyakit, pengajiran, dan pemanenan.

Pengamatan terhadap pertumbuhan $A$. pintoi meliputi persentase tumbuh pada 1-3 MST, persentase penutupan tanah oleh $A$. pintoi menggunakan metode kuadran $0,5 \mathrm{~m}$ x $0,5 \mathrm{~m}$ pada 15, 30, 45, 60, 75, 90 MST. Pengamatan pertumbuhan gulma dengan melakukan analisis vegetasi gulma pada saat umur 30, 60, 90 HST. Pertumbuhan tanaman tomat diamati pada 5 tanaman contoh setiap petak, meliputi tinggi tanaman, jumlah daun, umur berbunga, jumlah buah, bobot panen, bobot rata-rata per buah. Analisis tanah dilakukan secara komposit sebelum tanam dan pada akhir penelitian.

\section{HASIL DAN PEMBAHASAN} Pengaruh Jenis Stek dan Jarak tanam A. pintoi
Terhadap Persen Penutupan

Penutupan A. pintoi diamati menggunakan kuadran $0.5 \mathrm{~m}$ x $0.5 \mathrm{~cm}$. Perlakuan jarak tanam dan jenis stek berpengaruh terhadap kecepatan penutupan. Analisis sidik ragam pada pengamatan persen penutupan $A$. pintoi menunjukkan bahwa perlakuan jarak tanam tanam memberikan pengaruh yang sangat nyata terhadap persen penutupan pada 30 HST sampai dengan 90 HST. Pada 30 HST merupakan tahap awal pertumbuhan hampir semua perlakuan pertumbuhannya masih seragam karena mulai muncul tunas pada 2-3 MST.

Perlakuan jarak tanam dan jenis stek mempengaruhi kecepatan penutupan A. pintoi . Penutupan pada umur 90 MST perlakuan K4(99.61\%) dan K3(94.17\%) lebih cepat dibandingkan dengan K1(68\%) dan K2(82.17\%). Perlakuan jarak tanam K3 berbeda sangat nyata dengan $\mathrm{K} 2$ dan $\mathrm{K} 1$, tetapi antara $\mathrm{K} 1$ dan $\mathrm{K} 2$ tidak berbeda nyata (Tabel 1).

Hal ini diduga karena pada jarak tanam yang rapat tanaman memberikan jumlah tajuk yang lebih banyak, setiap stek menumbuhkan tunas-tunas yang terus menjalar menutupi ruangruang di antara tanaman yang masih kosong (Sumarni 2009).

Jenis stek yang paling cepat penutupanya adalah stek bagian pucuk. Meskipun kecepatannya antara bagian tengah dan pucuk tidak berbeda nyata. Menurut Hartman (2007) jenis stek pucuk lebih cepat berakar karena mengandung auksin yang tinggi.

Tabel 1. Nilai Rata-rata Persen Penutupan A. pintoi pada Perlakuan Jarak tanam dan Jenis Stek

\begin{tabular}{lrllll}
\hline Perlakuan & \multicolumn{5}{c}{ Penutupan \% } \\
\cline { 2 - 5 } & 30 HST & 45 HST & $60 \mathrm{HST}$ & $75 \mathrm{HST}$ & $90 \mathrm{HST}$ \\
\hline Jarak tanam & & & & & \\
K1 & $7.89 \mathrm{~b}$ & $19.33 \mathrm{c}$ & $35.00 \mathrm{c}$ & $51.06 \mathrm{c}$ & $68.00 \mathrm{c}$ \\
K2 & $6.83 \mathrm{~b}$ & $29.61 \mathrm{cb}$ & $48.56 \mathrm{cb}$ & $73.72 \mathrm{~b}$ & $82.17 \mathrm{~b}$ \\
K3 & $10.00 \mathrm{~b}$ & $40.28 \mathrm{~b}$ & $58.89 \mathrm{~b}$ & $82.94 \mathrm{ab}$ & $94.17 \mathrm{ab}$ \\
K4 & $14.00 \mathrm{a}$ & $61.94 \mathrm{a}$ & $83.50 \mathrm{a}$ & $99.61 \mathrm{a}$ & $99.61 \mathrm{a}$ \\
\hline Jenis stek & & & & & \\
J1 & 8.75 & $25.25 \mathrm{~b}$ & $58.17 \mathrm{~b}$ & $62.62 \mathrm{~b}$ & $76.29 \mathrm{~b}$ \\
J2 & 10.08 & $59.08 \mathrm{a}$ & $59.08 \mathrm{a}$ & $77.42 \mathrm{a}$ & $88.71 \mathrm{a}$ \\
J3 & 10.21 & $69.08 \mathrm{a}$ & $69.08 \mathrm{a}$ & $85.33 \mathrm{a}$ & $92.96 \mathrm{a}$ \\
\hline
\end{tabular}

Keterangan : nilai yang diikuti huruf yang sama pada kolom yang sama menunjukkan tidak berbeda nyata pada uji DMRT taraf $5 \%$.

K: jarak tanam; K1: $20 \mathrm{~cm}$ x $20 \mathrm{~cm}$; K2: $20 \mathrm{~cm}$ x $15 \mathrm{~cm}$; K3: $20 \mathrm{~cm}$ x $10 \mathrm{~cm}$; K4: $20 \mathrm{~cm}$ x $5 \mathrm{~cm}$. J: Jenis stek. J1: stek pangkal; J2: tengah; J3: pucuk

Menurut Huang et al. (2004) tanaman A. pintoi ini baik pada lahan tandus maupaun lahan subur semakin rapat jarak tanamnya penutupanya juga semakin cepat. Dari hasil penelitian tersebut pada umur $30 \mathrm{HST}$ jarak tanam $10 \mathrm{~cm} \times 10 \mathrm{~cm}$ penutupanya mencapai $78 \%$ di lahan subur, dan $49 \%$ di lahan tandus. Sedangkan jarak tanam 20 $\mathrm{cm} \times 20 \mathrm{~cm}$ penutupanya $41 \%$ di lahan subur dan $27 \%$ di lahan tandus.
Pengaruh Jenis Stek dan Jarak tanam A. pintoi Terhadap Pertumbuhan Gulma

Jenis gulma yang mendominasi sebelum dilakukan pengolahan adalah jenis gulma daun lebar Boreria alata dan Cleome rutidosperma, sedangkan golongan rumput Axonopus compressus, Digitaria adscendens dan Roetbolia exaltata. Jenis gulma pada anilisis vegetasi umur 
30 MST masih didominasi oleh jenis gulma daun lebar diantaranya Boreria alata dan Cleome rutidosperma. Hasil analisis pada umur 90 HST gulma yang mendominasi adalah golongan rumput. Hal ini diduga jenis gulma daun lebar mengalami penekanan oleh penutupan biomulsa A. pintoi. Jenis rumput tersebut yang paling dominan adalah spesies Axonopus compressus.

Hasil analisis vegetasi menunjukkan perlakuan jarak tanam mempengaruhi berat kering gulma. Jarak tanam A. pintoi yang tinggi dapat menekan pertumbuhan gulma. Perlakuan jarak tanam K1 dengan berat kering gulma $51.07 \mathrm{~g}$ dan perlakuan K4 $30.98 \mathrm{~g}$ (Tabel 2), berdasarkan hasil tersebut diduga perlakuan K4 dengan persen penutupan yang lebih cepat dapat menekan pertumbuhan gulma karena terjadi persaingan unsur hara, air, dan cahaya dengan A. pintoi.

Tabel 2. Pertumbuhan Gulma pada Umur 90 HST dengan Berbagai Perlakuan

\begin{tabular}{lccccccc}
\hline Perlakuan & \multicolumn{2}{c}{ Jumlah Jenis Gulma } & \multicolumn{2}{c}{$\begin{array}{c}\text { Nisbah Jumlah Dominasi } \\
\text { ( NJD) }\end{array}$} & \multicolumn{2}{c}{$\begin{array}{c}\text { Berat Kering } \\
\text { Gulma }(\mathrm{g})\end{array}$} & $\begin{array}{c}\text { Bk Gulma } \\
\text { Total (g) }\end{array}$ \\
\cline { 2 - 8 } & $\mathrm{R}$ & $\mathrm{DL}$ & $\mathrm{R}$ & $\mathrm{DL}$ & $\mathrm{R}$ & $\mathrm{DL}$ & \\
\hline Jarak tanam & & & & & & & \\
K1 & 4.67 & 3.00 & 84.80 & 15.20 & 46.10 & 4.97 & 51.07 \\
K2 & 4.00 & 2.67 & 82.16 & 17.84 & 33.60 & 3.64 & 37.24 \\
K3 & 3.67 & 4.33 & 73.08 & 26.92 & 26.91 & 7.18 & 34.09 \\
K4 & 2.33 & 2.00 & 87.21 & 12.79 & 28.86 & 2.13 & 30.98 \\
\hline Jenis stek & & & & & & & \\
J1 & 4.00 & 3.25 & 81.79 & 18.21 & 34.12 & 5.17 & 39.29 \\
J2 & 4.00 & 3.00 & 83.63 & 16.37 & 34.21 & 3.78 & 37.99 \\
J3 & 3.00 & 2.75 & 80.02 & 19.98 & 33.27 & 4.50 & 37.77 \\
\hline
\end{tabular}

Keterangan : nilai yang diikuti huruf yang sama pada kolom yang sama menunjukkan tidak berbeda nyata pada uji DMRT taraf $5 \%$.

K: jarak tanam; K1: $20 \mathrm{~cm}$ x $20 \mathrm{~cm}$; K2: $20 \mathrm{~cm}$ x $15 \mathrm{~cm} ; \mathrm{K} 3: 20 \mathrm{~cm}$ x $10 \mathrm{~cm}$; K4: $20 \mathrm{~cm}$ x $5 \mathrm{~cm}$. J: Jenis stek. J1: stek pangkal; J2: tengah; J3: pucuk

Pengaruh Perlakuan Terhadap Pertumbuhan Vegetatif dan Komponen Hasil Tanaman Tomat

Analisis statistika menunjukkan perlakuan jenis stek dan jarak tanam biomulsa tidak memberikan pengaruh yang nyata terhadap pertumbuhan tinggi dan jumlah daun tanaman tomat. Kecuali tinggi tanaman pada 7 MST tinggi tanaman perlakuan jarak tanam K1 berbeda nyata dengan keratapan $\mathrm{K} 2, \mathrm{~K} 3$, dan $\mathrm{K} 4$.

Tabel 3. Pengaruh Perlakuan terhadap Komponen Hasil Tanaman Tomat

\begin{tabular}{lccccc}
\hline Perlakuan & $\begin{array}{c}\text { Bobot per Buah } \\
\text { (gram) }\end{array}$ & $\begin{array}{c}\text { Jumlah Buah } \\
\text { per Tanaman }\end{array}$ & $\begin{array}{c}\text { Bobot buah per } \\
\text { Tanaman (gram) }\end{array}$ & $\begin{array}{c}\text { Jumlah Buah } \\
\text { Total Petak }\end{array}$ & $\begin{array}{c}\text { Bobot Buah } \\
\text { Total (gram) }\end{array}$ \\
\hline Jarak tanam & & & & & \\
K1 & 19.45 & 5.64 & 111.44 & 79.00 & 1617.22 \\
K2 & 19.19 & 5.82 & 113.00 & 73.11 & 1463.56 \\
K3 & 21.34 & 5.48 & 119.73 & 70.00 & 1432.89 \\
K4 & 22.46 & 5.75 & 129.64 & 74.00 & 1610.33 \\
\hline Jenis stek & & & & & \\
J1 & 20.32 & 5.85 & 120.50 & 78.67 & 1591.50 \\
J2 & 20.23 & 5.57 & 115.43 & 69.17 & 1420.83 \\
J3 & 21.29 & 5.61 & 119.43 & 74.25 & 1580.67 \\
\hline
\end{tabular}

Keterangan : nilai yang diikuti huruf yang sama pada kolom yang sama menunjukkan tidak berbeda nyata pada uji DMRT taraf $5 \%$. $\mathrm{K}$ : jarak tanam; K1: $20 \mathrm{~cm}$ x $20 \mathrm{~cm}$; K2: $20 \mathrm{~cm}$ x $15 \mathrm{~cm}$; K3: $20 \mathrm{~cm}$ x $10 \mathrm{~cm}$; K4: $20 \mathrm{~cm}$ x $5 \mathrm{~cm}$. J: Jenis stek. J1: stek pangkal; J2: tengah; J3: pucuk

Interaksi antara jarak tanam dan jenis stek juga tidak berpengaruh nyata terhadap tinggi dan jumlah daun tomat pada pertumbuhan 1-7 MST, Hal ini diduga tanaman tomat mampu beradaptasi dengan kondisi keberadaan tanaman biomulsa $A$. pintoi. Kondisi lingkungan yang terdapat disekitar tanaman tomat mampu memberikan pertumbuhan tinggi dan daun yang normal. 
Hasil analisis menunjukkan bahwa ratarata jumlah buah per tanaman tidak berbeda nyata. Jenis stek dan jarak tanam tanam $A$. pintoi tidak memberikan pengaruh yang nyata terhadap jumlah buah per tanaman. Kondisi lahan bermulsa A. pintoi memberikan lingkungan yang relatif seragam untuk pertumbuhan vegetatif maupun generative tanaman tomat, meskipun pada jarak tanam yang tinggi bobot buah per tanaman juga lebih tinggi, tetapi tidak berbeda nyata. Hal ini diduga karena penutupan mulsa dapat memberikan lingkungan tumbuh yang baik.

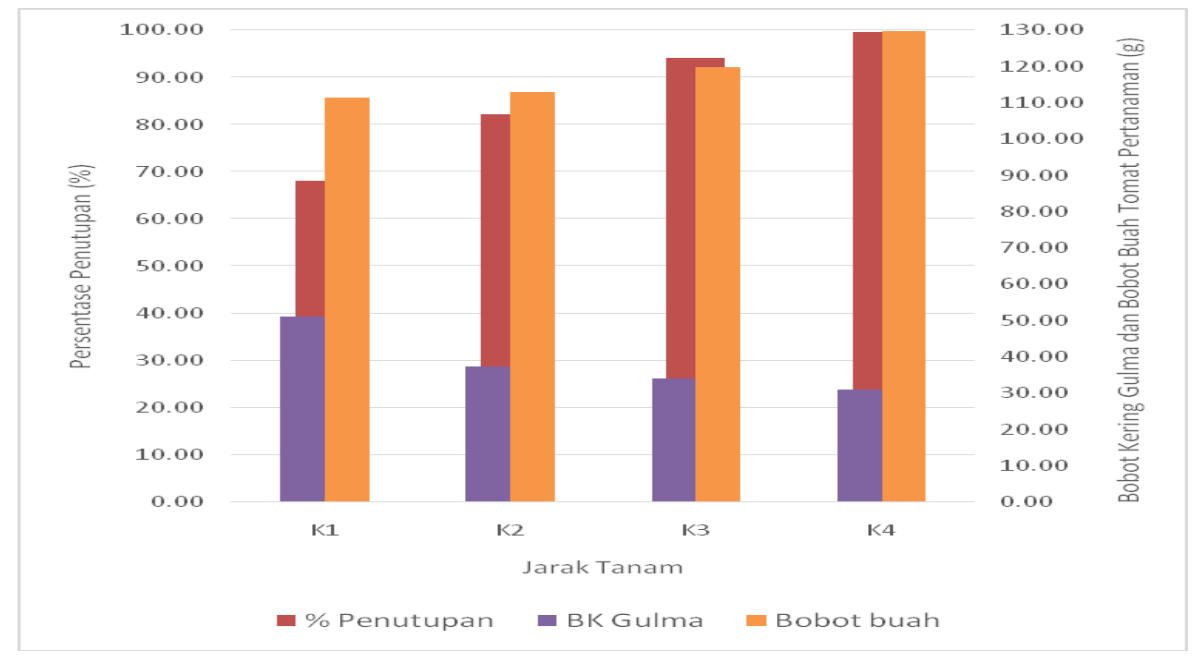

Gambar 1. Hubungan antara persentase penutupan Arachis pintoi, bobot kering gulma dan bobot buah tomat

Hubungan Antara Penutupan A. pintoi, Berat Kering Gulma dan Komponen Hasil Tanaman Tomat

Persaingan dalam mendapatkan unsur hara, air, dan cahaya diduga terjadi antara tanaman tomat, biomulsa $A$. pintoi, dan gulma. Pada persaingan ini terdapat beberapa hubungan yang saling terkait antara persen penutupan $A$. pintoi, berat kering gulma, dan bobot per tanaman tomat. Pada Gambar 1 terlihat jelas bahwa makin tinggi persentasi penutupan tanah oleh Arachis pintoi, makin rendah pertumbuhan gulma, makin tinggi produksi buah tomat.

\section{DAFTAR PUSTAKA}

Baharuddin, R. 2010. Penggunaan Kacang Hias (Arachis pintoi) sebagai Biomulsa pada Budidaya Tomat (Licopersicon esculentum M.). Skripsi. Departeman Agronomi dan Hortikultura IPB. Bogor.

Hartmann, H.T., D.E. Kester, F.T. Davies, and R. L. Geneve. 1997. Plant propagation principles and practices. 6th ed. Prentice Hall, Englewood Cliffs, N.J.

Huang, Y.B., T. Long, Z. Zhong, C. En, Y. Zhao. 2004. Utilization of Arachis pintoi in red soil region and its effciency on water-soil conservation in China. International Soil Conservation Organisation Conference. Brisbane.

Kartasapoetra, A. G., 1989. Kerusakan Tanah Pertanian dan Usaha untuk Merehabilitasinya. Bina Aksara. Jakarta.

Maswar. 2004. Kacang hias (Arachis pintoi) pada usaha tani lahan kering. Balai Penelitian Tanah. Bogor.

Pangaribuan, D.H, O.L. Pratiwi, Lismawanti. 2011. Pengurangan pemakaian pupuk anorganik dengan penambahan bokashi. serasah tanaman pada budidaya tanaman tomat. J. Agron. Indonesia 39 (3) : 173 179

Sumarni, N., A. Hidayat, dan E. Surniati. 2006. Pengaruh tanaman penutup tanah dan mulsa organik terhadap produksi cabai dan erosi tanah. J.hort.16(3):197-201.

Sumarni, N., E. Sumiati, R. Rosliani. 2009. Respon tanaman mentimun terhadap penggunaan tanaman penutup tanah kacang-kacangan dan mulsa jerami. J.hort. (19)3: 294-300 